\title{
EXTRACT OF Punica granatum L.: AN ALTERNATIVE TO BHT AS AN ANTIOXIDANT IN SEMISSOLID EMULSIFIED SYSTEMS
}

\author{
Jéssica Tiago Tozetto ${ }^{a}$, Andressa Tiago Tozetto ${ }^{a}$, Bernardo Teixeira Hoshino ${ }^{a}$, Carla Regina Andrighetti ${ }^{a}$, Elton Brito \\ Ribeiro $^{a}$, Larissa Cavalheiro ${ }^{\mathrm{b}}$ and Stela Regina Ferrarini ${ }^{\mathrm{a}, *}$ \\ anstituto de Ciências da Saúde, Universidade Federal do Mato Grosso, 78550-728 Sinop - MT, Brasil \\ 'Instituto de Ciências Naturais, Humanas e Sociais, Universidade Federal do Mato Grosso, 78550-728 Sinop - MT, Brasil
}

Recebido em 26/04/2016; aceito em 04/08/2016; publicado na web em 26/08/2016

\begin{abstract}
Pomegranate (Punica granatum L.) is a fruit which has important pharmacological activities and has been attracting attention due to its important antioxidant activity, a significant feature in relation to cosmetics. Formulations containing different concentrations of an ethanolic extract of pomegranate $(0.1,1.0$ and $5.0 \%)(\mathrm{w} / \mathrm{w})$ as an antioxidant agent showed that this is an interesting alternative for the use of natural products with biological activity. The stability and rheology of semissolid systems containing an extract of this plant were evaluated. Preliminary stability studies showed greater physico-chemical stability of the formulation, and thus it was used in an accelerated stability study, as well the quantification of total phenolic compounds and the determination of antioxidant activity. It was observed that different concentrations of the extract did not significantly influence the stability. Moreover, the formulation was found to have better stability when stored at room temperature than under heated or cooled conditions. Formulations containing 0.1 and $5.0 \%$ of extract showed more stable rheological behavior, due to the absence of a solid/liquid transition in the rheogram. Tests confirmed the high phenolic content and antioxidant activity, demonstrating the potential of this plant for use in cosmetology as an antioxidant.
\end{abstract}

Keywords: antioxidant activity; cosmetic formulations; pomegranate extract (Punica granatum L.); skin aging.

\section{INTRODUCTION}

Skin aging is related to the action of reactive oxygen species (ROS) which are present in greater quantities and are thus not eliminated. These molecules interact with cells present in our body and may cause changes, which are harmful in many cases. ${ }^{1}$ Skin aging is the result of oxidative action on the cells which can be avoided by using substances with antioxidant action, which reduce or inhibit cellular oxidation. ${ }^{2}$ In the cosmetic industry, aging caused by oxidation is counteracted with the use of ROS scavengers. The antioxidant activity allows users to benefit from emulsions to combat aging by reducing the levels of ROS. The most commonly used compounds for this purpose are butylated hydroxytoluene (BHT), butylated hydroxyanisole (BHA), trihydroxybutylphenone (THBP), terc-butyl hydroxiquinone (TBHQ) and propylgallate (PG). BHT is a synthetic antioxidant widely used in emulsions, with extensive application in the cosmetic area. Some studies have demonstrated that these antioxidant compounds can present toxic effects. ${ }^{3,4}$ Animal studies show that acute and prolonged exposure to these compounds may lead to the development of tumors in the liver and pancreas glands. They also increased the $\mathrm{H}_{2} \mathrm{O}_{2}$ formation in microsomes, altering liver function, and causing adenomas and carcinomas in the liver cells and carcinogenesis in the stomach of rats. ${ }^{5}$ Thus, researchers have been trying to find natural compounds with antioxidant activity, ${ }^{4-7}$ thereby allowing the replacement of these synthetic compounds or their combination with natural substances, combating premature aging by reducing ROS levels. Pomegranate (Punica granatum L.) is an example of a plant containing antioxidants which has applications in the cosmetics, food and pharmacotherapy industries. It belongs to the Lythraceae family, which is comprised of 10 genera and around 150 species. One of the factors that have contributed to the growth of the cosmetics industry is the increased demand for products that reduce skin aging. ${ }^{8}$ Therefore, one application of this extract with added value is its incorporation into semissolid topical

*e-mail: stelareginaferrarini@yahoo.com.br application systems, such as emulsions. Emulsions are vehicles with a chemical constitution similar to that of skin, with increased permeability when compared to vehicle solutions and gels, which do not permeate the skin because they have a non-lipid character. Lanette cream base has higher contents of fatty alcohols, alkyl sulfate, moisturizers and low oiliness emollients in its composition, along with a soft touch and high resistance to active ingredients that require vehicles with these characteristics. This cosmetic base features compatibility with all cosmetics and pharmaceuticals that tolerate anionic emulsions. It has been observed that an anionic emulsion (Lanette cream) provides better penetration into the skin than a non-ionic cream (Paramul cream), ${ }^{9}$ suggesting the use of the former as a base for the preparation of cosmetics containing pomegranate extract.

The bark of this plant is an important source of antioxidants, since it contains phenolic compounds, including hydroxycinnamic acids, ellagic acid, catechins, epicatechins, and protoantocianidinas proanthocyanidins, quercetin, kaempeferol, luteolin, naringin, and punicalagin. ${ }^{5,10}$ In the cosmetology area, experiments using an aqueous extract of the fruit peel verified its capacity to stimulate collagen synthesis and the proliferation of dermal fibroblasts, also inhibiting the enzyme (MMP-1), which is responsible for the destruction of collagen in aged skin. ${ }^{11}$ Therefore, it is important to develop dermatological and cosmetic formulations containing antioxidants of vegetable extracts, such as of pomegranate extract. Since most of these extracts have lower toxicity compared to synthetic compounds, such as BHT, they are appropriate for many cosmetic and dermatological products.

\section{EXPERIMENTAL SECTION}

\section{Materials and reagents}

Pomegranate (Punica granatum L.) was collected in the town of Sinop (S 11051'23.32; 55031'03.77 W). The botanical evaluation and plant identification were carried out at the Biological Collection 
of Southern Amazon (ABAM) of UFMT, Sinop Campus, where a voucher specimen is deposited under the registration number of 6462. All solvents and reagents used were of analytical grade. Folin-Ciocalteu's reagent was purchased from Merck, the DPPH (2,2-diphenyl-1-picrylhydrazyl) radical from Aldrich Co., gallic acid from Vetec and ascorbic acid from Synth.

\section{Obtaining the pomegranate bark extract}

The fruit identification confirmed that the sample was Punica granatum L. The ethanol extract was obtained by maceration of the fruit bark previously dried at room temperature and protected from light. The dried bark was placed in contact with $70 \%$ ethyl alcohol in a proportion of $20 \%(\mathrm{w} / \mathrm{v})$ at room temperature and stirred daily for a period of fifteen days. After this period, the extract was filtered and concentrated with a rotating evaporator and dried in an oven at $40{ }^{\circ} \mathrm{C}$, since at this temperature there is no degradation of the compounds presented in the extract. The sample was packed into an amber container to minimize contact with light, which can cause oxidation of the extract and lead to a loss of activity. ${ }^{12}$ The macroscopic characteristics and $\mathrm{pH}$ were evaluated.

\section{Development of anionic semissolid emulsions}

To prepare the semissolid emulsion base, the components of the oil phase [Lanette ${ }^{\circledR}(250 \mathrm{~g})$, liquid petrolatum $(45 \mathrm{~mL})$ and propylparaben $(2.25 \mathrm{~g})]$ and the components of the aqueous phase [propylene glycol $(105 \mathrm{~mL})$, methylparaben $(2.25 \mathrm{~g})$ and distilled water $(1105.5 \mathrm{~mL})]$ were heated to $75^{\circ} \mathrm{C}$ and $80^{\circ} \mathrm{C}$, respectively. The aqueous phase was added to the oil phase, stirring vigorously for $10 \mathrm{~min}$. After cooling the base, pomegranate extract was incorporated at three different concentrations $0.1,1.0$ and $5.0 \% .{ }^{13}$ The concentrated extract was incorporated into the semissolid base at room temperature. The anionic creams were represented by acronyms according to the type and concentration of active substance as follows: emulsion containing $0.1 \%\left(\mathrm{E}_{0.1}\right), 1.0 \%\left(\mathrm{E}_{1.0}\right)$ and $5.0 \%\left(\mathrm{E}_{5.0}\right)$ of the pomegranate extract. An emulsion without pomegranate extract and a formulation containing an antioxidant widely used in cosmetology, $0.1 \%$ BHT, were also prepared and named white emulsion $\mathrm{E}_{\mathrm{Br}}$ and $\mathrm{E}_{\mathrm{BHT}}$, respectively.

\section{Determination of total phenol and polyphenol contents}

The content of phenolic compounds in the pomegranate extract, alone or incorporated into the emulsions, and also in the emulsions containing BHT, were determined by the Folin-Ciocalteu method. ${ }^{14}$ The emulsions containing BHT were used as references for comparison, since BHT is a synthetic antioxidant commonly applied in cosmetics. To prepare the samples, $100 \mathrm{mg}$ of concentrated extract was used, which was transferred to a $100 \mathrm{~mL}$ volumetric flask, completing the volume with methanol. From this dilution, a sample $(7.5 \mathrm{~mL})$ was collected and transferred to a volumetric flask (50 $\mathrm{mL}$ ), completing the volume with methanol. The procedure involved placing $100 \mu \mathrm{L}$ of this final dilution of the sample, $500 \mu \mathrm{L}$ of FolinCiocalteu and $6 \mathrm{~mL}$ of distilled water in a test tube. In the next step, $6 \mathrm{~mL}$ of a $15 \%$ sodium carbonate solution was added, followed by stirring for a few seconds, and the tubes were kept in a water bath at $37^{\circ} \mathrm{C}$ for a period of $2 \mathrm{~h}$, protected from light. The absorbance of the samples was measured on a spectrophotometer (Spectrum SP-1105) at $750 \mathrm{~nm}$. The total phenols and polyphenols content of the emulsions were determined in the same way, considering the concentration of extract or BHT incorporated into the base. Gallic acid was used as a reference standard, constructing a standard curve at concentrations of $10,25,50,100,200$ and $300 \mu \mathrm{g} \mathrm{mL}^{-1}$ of gallic acid, in triplicate.

\section{In vitro antioxidant activity evaluation}

The antioxidant activity was determined as the ability of the antioxidants present in the samples to sequester the stable radical $\mathrm{DPPH}^{\cdot}$ at $517 \mathrm{~nm} .{ }^{15}$ This assay was performed with the plant extract and with all emulsions investigated in this study $\left(\mathrm{E}_{\mathrm{Br}}, \mathrm{E}_{\mathrm{BHT}}, \mathrm{E}_{0.1}\right.$, $\mathrm{E}_{1.0}$ and $\mathrm{E}_{5.0}$ ). The analysis were performed on day zero ( $24 \mathrm{~h}$ after the preparation of the samples) and after the accelerated stability evaluation as a function of time and the temperature conditions. Under protection from light, $1 \mathrm{~mL}$ of the sample was placed into a test tube and diluted with methanol $(n=3)$. The dilutions were then added to $3 \mathrm{~mL}$ of a methanol solution containing the DPPH free radical. A control solution containing $3 \mathrm{~mL}$ of DPPH and $1 \mathrm{~mL}$ of methyl alcohol was also prepared. Methyl alcohol was used as the blank solution in order to calibrate the spectrophotometer (Spectrum SP-110). The tubes containing the samples were left to stand at room temperature for $30 \mathrm{~min}$ protected from light. Based on the results, the percentage of DPPH remaining in the reaction medium and/or the percentage of antioxidant activity was determined. The percentage of antioxidant activity (\% AA) represents the inhibition of the DPPH free radical by the antioxidant and it was calculated according to the following equation:

$$
\mathbf{A A} \%=\left\{\left[\left(\mathbf{A b s}_{\text {sample }}-\mathbf{A b s}_{\text {white }}\right) \times \mathbf{1 0 0}\right] / \mathbf{A b s}_{\text {control }}\right\}
$$

The standard curve was obtained for concentrations of between 5 and $150 \mu \mathrm{g} \mathrm{mL}^{-1}$ of ascorbic acid, ${ }^{16}$ as determined from the linear equation. All experiments were performed in triplicate.

\section{Preliminary stability analysis}

The preliminary stability test was carried out in triplicate with evaluation by macroscopic analysis, $\mathrm{pH}$ testing, thermal stress, centrifugation, freezing and thawing cycles and a rheological assessment. The samples $\left(\mathrm{E}_{0.1}, \mathrm{E}_{1.0}, \mathrm{E}_{5.0}, \mathrm{E}_{\mathrm{BHT}}, \mathrm{E}_{\mathrm{Br}}\right)$ were stored at room temperature and analyzed on day zero ( $24 \mathrm{~h}$ after formulation) and after the freeze-thaw cycle, with the exception of the rheological evaluation which was carried out on day zero.

\section{Macroscopic analysis}

The macroscopic characteristics were determined in accordance with the visual aspects (including color, flavor, viscosity) displayed by the formulations. The parameters evaluated were: appearance, color, odor and homogeneity. ${ }^{11}$

\section{Thermal stress}

The samples were submitted to heating in a water bath (Quimis Q334M-28 Model) for $30 \mathrm{~min}$. The heating was carried out gradually up to $80{ }^{\circ} \mathrm{C}$ and this temperature was held for $30 \mathrm{~min} .{ }^{17}$

\section{Freezing and thawing cycle}

The samples were placed in a freezer at $-5 \pm 2{ }^{\circ} \mathrm{C}$ for $24 \mathrm{~h}$ and then in an oven at $40 \pm 2{ }^{\circ} \mathrm{C}$ for $24 \mathrm{~h}$, thereby completing one cycle. Six freeze-thaw cycles were performed, totaling 12 days of testing. ${ }^{18}$

\section{Centrifugation test}

A sample of $5 \mathrm{~g}$ of each emulsion (kept at room temperature, after being subjected to thermal stress, and after the freeze-thaw cycle) was placed in a conical test tube. The sample was subjected to centrifugation (Fanem - Excelsa II - Model 206 BL) at 1000, 2500 and $3500 \mathrm{rpm}$, for $15 \mathrm{~min}$ at each rotation speed at room temperature. ${ }^{17}$ 
pH analysis

The determination of the $\mathrm{pH}$ of the samples (extract and emulsions) was carried out by diluting them in distilled water (1:20 $\mathrm{w} / \mathrm{v}$ ) at $25{ }^{\circ} \mathrm{C}$. The $\mathrm{pH}$ meter (Tecnopon-Model mPA210) was calibrated with standard solutions at known $\mathrm{pH}$ (4.0 and 6.0). The analysis was performed in triplicate. ${ }^{18}$

\section{Rheological analysis}

The rheological characteristics of the formulations were determined using a Modular Compact Rheometer - MCR 102 (Anton $\left.\mathrm{Paar}^{\circledR}\right)$. In all experiments, the formulations were placed on the reading surface of the plate and the excess was removed. Readings were taken with permanent control of the measuring gap with TruGap ${ }^{\mathrm{TM}}$ support at $0.099 \mathrm{~mm}$, a Toolmaster CP $50^{\mathrm{TM}}$ measuring cell and precise temperature control with a T-Ready ${ }^{\mathrm{TM}}$ (Rheoplus Software V3.61). The rheological data were all treated with the Rheoplus Software. The oscillation tests were performed with a constant oscillatory amplitude voltage of $0.5 \mathrm{~Pa}$. The measurements were performed as a function of the frequency $(\mathrm{Hz})$ ranging from 100 to $0.1 \mathrm{~Hz}$.

\section{Accelerated stability}

The accelerated stability tests were performed with the emulsion containing the pomegranate extract which was considered to be the most stable based on preliminary stability tests $\left(\mathrm{E}_{5.0}\right)$. The control formulations $\left(\mathrm{E}_{\mathrm{Br}}\right.$ and $\left.\mathrm{E}_{\mathrm{BHT}}\right)$ were also subjected to three different temperature conditions: $4 \pm 2{ }^{\circ} \mathrm{C}$ (Refrigerator Consul Compact 120 liters), $25 \pm 2{ }^{\circ} \mathrm{C}$ (controlled room temperature) and $45 \pm 2{ }^{\circ} \mathrm{C}$ (Climate New House ethics 420 - 300 CLD) over 90 days. ${ }^{9,19}$ Analysis was performed at 30-day intervals (day 0, 30, 60 and 90) and the parameters evaluated were: macroscopic characteristics, $\mathrm{pH}$, in vitro antioxidant activity and spreadability.

\section{Spreadability evaluation}

The spreadability was determined according to the method described by Borguetti. ${ }^{20} \mathrm{~A}$ circular glass plate (diameter of $20 \mathrm{~cm}$ and thickness of $0.2 \mathrm{~mm}$ ) with a central orifice of $1.2 \mathrm{~cm}$ diameter was used. A glass support plate $(20 \mathrm{~cm} \times 20 \mathrm{~cm})$ was positioned on a millimeter scale. The sample was introduced into the hole of the plate mold and the surface was leveled with a spatula. The plaque was then removed and over it was placed a known weight. After $1 \mathrm{~min}$, a reading was taken of the diameter covered by the sample. Subsequently, the average diameter was calculated. The results were expressed as spreadability of the sample as a function of the applied weight, according to the equation below, and the values correspond to the average of three determinations:

$$
\mathbf{E i}=\mathbf{d}^{2} \mathbf{x} \frac{\pi}{4}
$$

where: $\mathrm{Ei}=$ spreadability of the sample for a certain weight $\mathrm{i}\left(\mathrm{mm}^{2}\right)$ and $\mathrm{D}=$ mean diameter $(\mathrm{mm})$.

\section{Statistical analysis}

The results reported herein are the average of three repetitions $(\mathrm{n}=3) \pm$ standard deviation. The antioxidant activity results which indicated the probability of the null hypothesis to be lower than $5 \%(\mathrm{P}$ $<0.05$ ), applying ANOVA followed by Tukey's multiple comparison test, were considered statistically different.

\section{RESULTS AND DISCUSSION}

\section{Obtaining the ethanolic pomegranate bark extract}

Results reported in the literature regarding the quality and quantity of ethanol extracts vary according to the method used. ${ }^{11}$ The maceration method used to obtain the ethanol extract in this study was found to be able to extract hydrophilic compounds, with $58.00 \%$ yield of crude extract. The specifications are consistent with Trindade. ${ }^{21}$ The extract obtained was a liquid of low viscosity, brown to yellowish brown, with characteristic odor and $\mathrm{pH}$ of $3.77 \pm 0.02$ [concentration of $1 \mathrm{mg} \mathrm{mL}^{-1}(\mathrm{w} / \mathrm{v})$ ].

\section{Preparation of anionic emulsions}

The emulsions prepared without the incorporation of pomegranate extract and the formulations containing BHT as an antioxidant were macroscopically white while the creams containing pomegranate extract were slightly yellowish. This color was expected since the extract has a yellowish brown color. Greater color intensity was observed with increasing active concentration in the cosmetic base.

\section{Evaluation of total phenolic content in the extracts}

Several methods are available for the quantification of total phenols and one of the most extensively used is a colorimetric method employing Folin-Ciocalteu's reagent. ${ }^{2,22}$ This reagent is composed of phosphomolybdic and phosphotungstic acids, where molybdenum and tungsten are in the oxidation state $6+$. In the presence of certain reducing agents (phenolic compounds, for example), molybdenum blue and tungsten blue are formed. ${ }^{23}$ The antioxidant activity of phenolic compounds is mainly related to their chemical structure and reducing characteristics. These properties are important in the process aimed at the neutralization of reactive oxygen species, acting on the initiation step and/or preventing the progress of the oxidative process. ${ }^{24}$ The total phenols contents of the pomegranate extract and the formulations were determined by the Folin-Ciocalteu method and expressed in milligrams of gallic acid equivalents per gram $(\mathrm{mgGAE} / \mathrm{g}$ ). The equation for the curve was $\mathrm{y}=0.0117 \mathrm{x}-0.0532$, and the correlation coefficient obtained for the mean curve was 0.9993 (Figure 1).

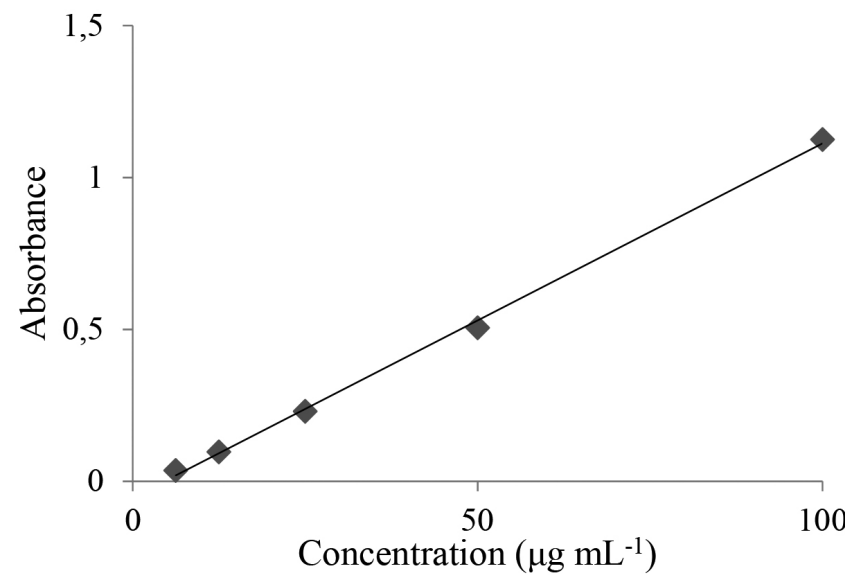

Figure 1. Linearity for total phenols obtained with the Folin-Ciocalteau $\operatorname{method}(n=3)$

The extract obtained had a total phenols concentration of $58.25 \pm$ $0.06 \mathrm{mgGAE} / \mathrm{g}$ of dry extract. This value is higher than that observed in the study conducted by Barros (2011), where the concentration for an ethanol extract of pomegranate was $36 \mathrm{mgGAE} / \mathrm{g}$. In a study by Gozlekçi, ${ }^{25}$ pomegranate bark was found to have a higher total phenolics content, with a value of $2747 \mathrm{mg} \mathrm{L}^{-1}$, when compared with the juice and seed of this fruit. For the emulsions, a correlation between the antioxidant activity of these pharmaceutical preparations and the content of soluble phenolic compounds was observed. The 
phenolic compounds incorporated into the emulsions were prepared in a concentration of $1 \mathrm{mg} \mathrm{mL}^{-1}$ and easily quantified. The results for the emulsions $\mathrm{E}_{0.1}, \mathrm{E}_{1.0}, \mathrm{E}_{5.0}$ and $\mathrm{E}_{\mathrm{BHT}}$ were (in $\mathrm{mgGAE} / \mathrm{g}$ of formulation), respectively, $54.87( \pm 0.10), 56.10( \pm 0.10), 54.0( \pm$ $0.12)$ and $58.22( \pm 0.10)$.

\section{Antioxidant activity evaluation with DPPH}

The evaluation of the in vitro antioxidant activity was carried out applying a spectrophotometric method with the use of DPPH. This method is considered to be accurate, fast, simple and of low cost and it is suitable for the determination of the antioxidant capacity of pure chemicals and complex mixtures of compounds, such as extracts obtained from plants. The assessment of the in vitro antioxidant activity (AA\%) through the use of the DPPH radical (2,2-diphenyl-1-picrylhydrazyl) was evaluated by observing the color change from purple to yellow, indicating that the samples were able to reduce this radical. The ethanolic extracts, obtained by the maceration method, and the emulsions were able to react with DPPH, showing a correlation between the total phenolics content and the antioxidant activity. The experiments revealed a greater activity for the concentrated extract, which reduced in accordance with the dilutions. This was also observed for the formulations with different extract concentrations, with a proportional dose/response relationship. For this test, emulsions containing BHT in the concentration generally used to achieve antioxidant activity $(0.1 \%)$ were used. It was also observed that the cream base showed no antioxidant activity and that it does not interfere with the activity of the ethanolic extract, demonstrating the specificity of the method. Regarding the comparison between the in vitro antioxidant activity of the extract of natural origin and the commercial antioxidant commonly used for this purpose in cosmetic formulations, it was observed that there was parity with regard to the radical reduction capacity. Thus, the ethanolic extract of the pomegranate bark, at the same concentration as the BHT, showed equivalent activity in both of the pure extracts, with no significant difference being observed (Figure 2).

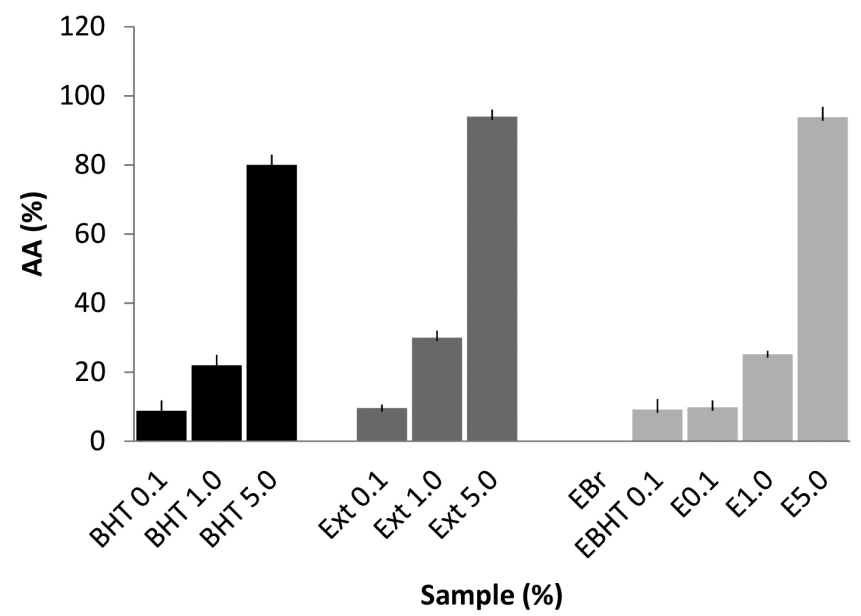

Figure 2. In vitro antioxidant activity determined by DPPH method ( $n=3)$

In this study, BHT was used in the concentration generally applied in cosmetic formulations $(0.1 \%)$ in order to mimic a practical situation commonly occurring in the cosmetics industry. ${ }^{26}$ The pomegranate extract was found to be an interesting alternative as an antioxidant in cosmetic formulations. This high level of antioxidant activity was also reported by Fischer, ${ }^{27}$ who observed a $68.3 \%$ DPPH reduction for 10 ppm of pomegranate bark. Fischer also evaluated the pomegranate pulp and seeds, which showed DPPH reductions of 0.8 and $0.2 \%$, respectively. This demonstrates that the bark of the fruit, the part usually discarded during consumption, has the highest antioxidant capacity.

\section{Preliminary stability}

Macroscopically, the formulations prepared $\left(\mathrm{E}_{\mathrm{Br}}, \mathrm{E}_{\mathrm{BHT}}, \mathrm{E}_{0.1}\right.$, $\mathrm{E}_{1,0}$ and $\mathrm{E}_{5.0}$ ), kept at room temperature and subjected to thermal stress, proved to be stable emulsions with the aspect of a cream, formulations containing the extract presenting the characteristic color of pomegranate oil while the others remained white. These characteristics were maintained over the entire study period (12 days). The evaluation of the stability of emulsions should be carried out using methods that accelerate instability by subjecting the formulation to stress conditions, such as thermal variation and exposure to light. ${ }^{28}$ In this context, thermal stress test were carried out, in which the physico-chemical interactions between raw materials are accelerated by increasing the temperature within a short period of time. In this study, as expected, the components were fused during heating, since the final temperature is higher than the melting point of the mixture. On cooling, all emulsions returned to their original semissolid state showing stability with respect to changes in color, odor and appearance, and indicating no signs of phase separation, coalescence, gas release, color change, or viscosity. In this assay, physico-chemical stability of the formulations was evaluated and, for this, the components of the formulations were completely fused. The stability of the phenolic compounds on heating was not assessed because this was a preliminary assessment in which the emulsion storage temperature was not investigated. However, the stability of the phenolic compounds was studied during accelerated stability testing.

Another effective procedure for the determination of the physical stability of the emulsified product is the centrifuge test. In this assay there is a modification of the gravity conditions, which accelerates the physical processes of sedimentation, coalescence or creaming in the system by separating the aqueous and oil phase through a density difference. ${ }^{29}$ None of the formulations used in the study showed physical instability, such as phase separation (coalescence, creaming or flocculation) after centrifugation, the thermal stress test or freeze-thaw cycles followed by centrifugation during the study period. Thus, all formulations were stable and suitable for further studies. The ethanolic extract was not adversely affected by thermal stress. In addition, the $\mathrm{pH}$ values for the ethanolic extract and the emulsions were determined and the $\mathrm{pH}$ results for the samples at time zero are shown in Table 1.

Table 1. $\mathrm{pH}$ analysis of the preliminary stability at time zero $(\mathrm{RSD}=$ relative standard deviation; $\mathrm{n}=3$ )

\begin{tabular}{cccc}
\hline Sample & $\mathrm{pH}^{*}$ & $\mathrm{pH}^{* *}$ & $\mathrm{RSD}(\%)$ \\
\hline Ext & $3.77 \pm 0.20$ & $3.81 \pm 0.15$ & 0.34 \\
$\mathrm{E}_{\mathrm{Br}}$ & $6.99 \pm 0.10$ & $7.00 \pm 0.07$ & 0.10 \\
$\mathrm{E}_{\mathrm{BHT}}$ & $6.78 \pm 0.19$ & $6.91 \pm 0.29$ & 1.34 \\
$\mathrm{E}_{0.1}$ & $7.00 \pm 0.13$ & $6.71 \pm 0.10$ & 2.99 \\
$\mathrm{E}_{1.0}$ & $5.97 \pm 0.21$ & $5.79 \pm 0.14$ & 2.16 \\
$\mathrm{E}_{5.0}$ & $5.58 \pm 0.08$ & $5.51 \pm 0.15$ & 0.89 \\
\hline
\end{tabular}

$* \mathrm{pH}$ before thermal stress; $* * \mathrm{pH}$ after thermal stress.

A reduction in the $\mathrm{pH}$ of the emulsions can be noted with increasing extract concentration (Table 1). Moreover, it was observed that there was no significant difference between the hydrogen potential values before and after heat stress, demonstrating the stability of the 
emulsions regarding this parameter. New formulations were prepared and then submitted to cycles of freezing and thawing. Macroscopic analysis and the determination of the $\mathrm{pH}$ of the samples, with and without the application of heat stress, were then performed (Table 2 ). The samples maintained the same characteristics observed before the freeze-thaw cycles, both for samples submitted to heat stress and those maintained under normal conditions. Casteli ${ }^{30}$ observed phase separation in three out of seven samples submitted to heat stress. Similar results were observed by Morais ${ }^{6}$ for five out of eighteen samples when submitted to centrifugation, and only one of the formulations did not show phase separation. Additionally, in this same study, after being subjected to the freeze-thaw cycle, with and without combined centrifugation, all samples maintained their initial characteristics. Thus, the anionic formulations developed are more stable than those reported in the literature.

Table 2. Results for $\mathrm{pH}$ obtained in the preliminary stability tests after the freeze-thaw cycle $(\mathrm{RSD}=$ relative standard deviation; $\mathrm{n}=3$ )

\begin{tabular}{cccc}
\hline Sample & $\mathrm{pH}^{*}$ & $\mathrm{pH}^{* *}$ & $\mathrm{RSD}(\%)$ \\
\hline $\mathrm{E}_{\mathrm{Br}}$ & $7.00 \pm 0.01$ & $6.90 \pm 0.33$ & 1.01 \\
$\mathrm{E}_{\mathrm{BHT}}$ & $6.79 \pm 0.20$ & $6.97 \pm 0.10$ & 1.84 \\
$\mathrm{E}_{0.1}$ & $6.97 \pm 0.07$ & $6.70 \pm 0.27$ & 2.79 \\
$\mathrm{E}_{1.0}$ & $5.95 \pm 0.09$ & $5.75 \pm 0.30$ & 2.41 \\
$\mathrm{E}_{5.0}$ & $5.70 \pm 0.10$ & $5.58 \pm 0.05$ & 1.50 \\
\hline
\end{tabular}

*pH after thermal stress; ** before thermal stress.
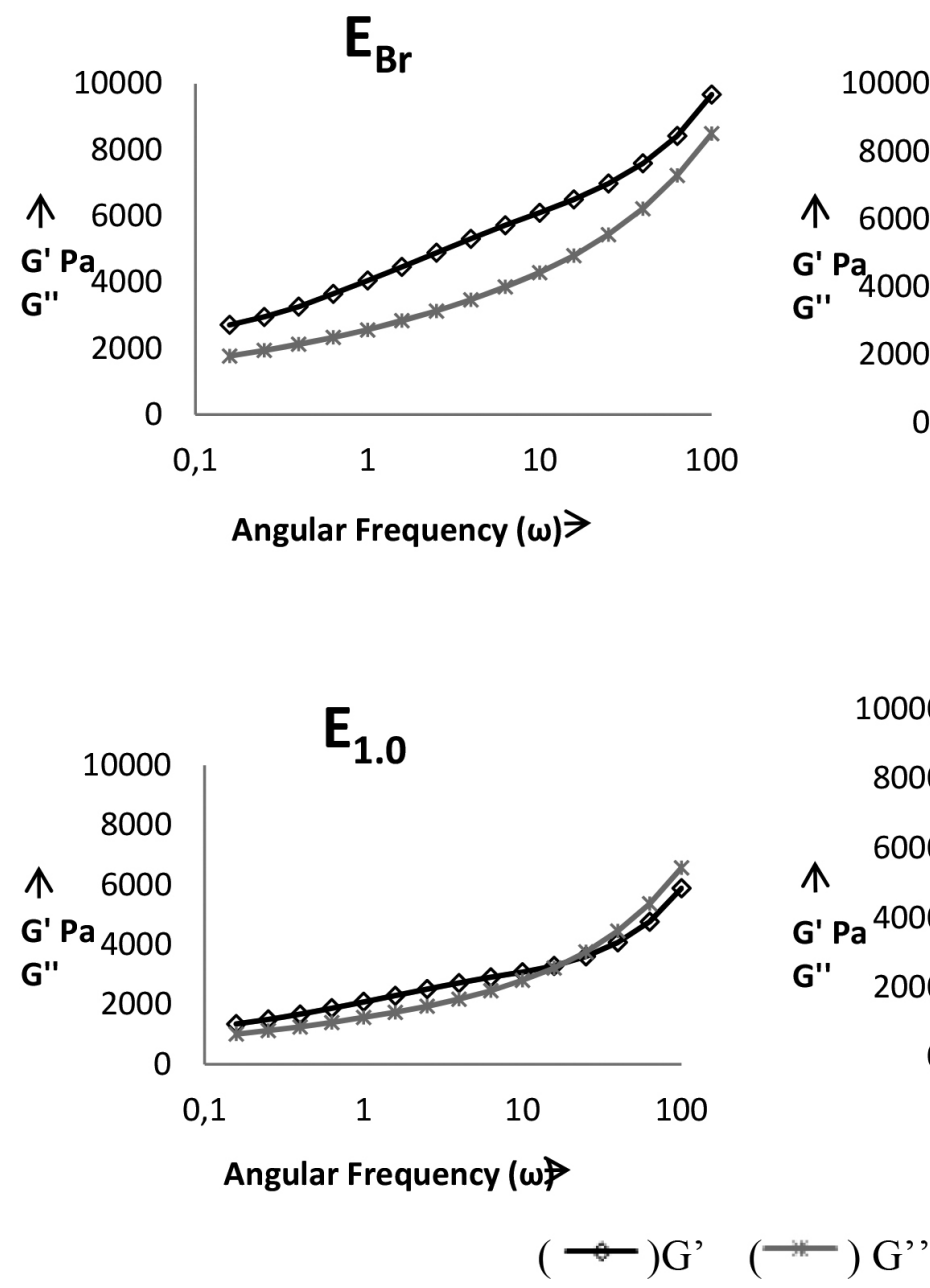

Figure 3. Dynamic oscillatory results for the formulations
The freeze-thaw cycle caused a slight variation in the $\mathrm{pH}$ of all samples, including the white emulsion and the emulsion containing a higher concentration of the vegetable extract. The formulations with minor changes in this parameter were $\mathrm{E}_{\mathrm{Br}}$ and $\mathrm{E}_{5.0}$, but no samples obtained a variation higher than those recommended by current legislation. ${ }^{18}$ It was noted that when analyzing the $\mathrm{pH}$ at time zero and the $\mathrm{pH}$ after the freeze-thaw cycle without heat stress, no significant changes were observed. The same scenario was observed in a study by Pianovski, ${ }^{17}$ who evaluated emulsions containing pequi oil and changes in $\mathrm{pH}$ after freezing and thawing cycles were minimal.

\section{Rheological evaluation}

The graphs in Figure 3 show the evolution of the storage modules G' (elastic modulus/solid elastic) and loss G' (viscous modulus/ viscous liquid) as a function of frequency. The first graph represents the oscillatory dynamic testing of the control formulation and the others an analysis of the semissolid formulations $\mathrm{E}_{0.1}, \mathrm{E}_{1.0}$ and $\mathrm{E}_{5.0}$ respectively.

For the control formulation $\left(\mathrm{E}_{\mathrm{Br}}\right)$, at $25{ }^{\circ} \mathrm{C}$, the $\mathrm{G}$ ' values are generally much higher than the G" values, suggesting a considerable presence of elastic interactions, forming a structured network. Therefore, the system is characterized as predominantly solid with elastic characteristic. This characteristic was also observed for the $\mathrm{E}_{0.1}$ formulation, behavior consistent with a study by Vianna Filho ${ }^{31}$ in which emulsions with polysaccharide added were investigated. In the cited study, all of the samples obtained $\mathrm{G}^{\prime}$ values higher than G"
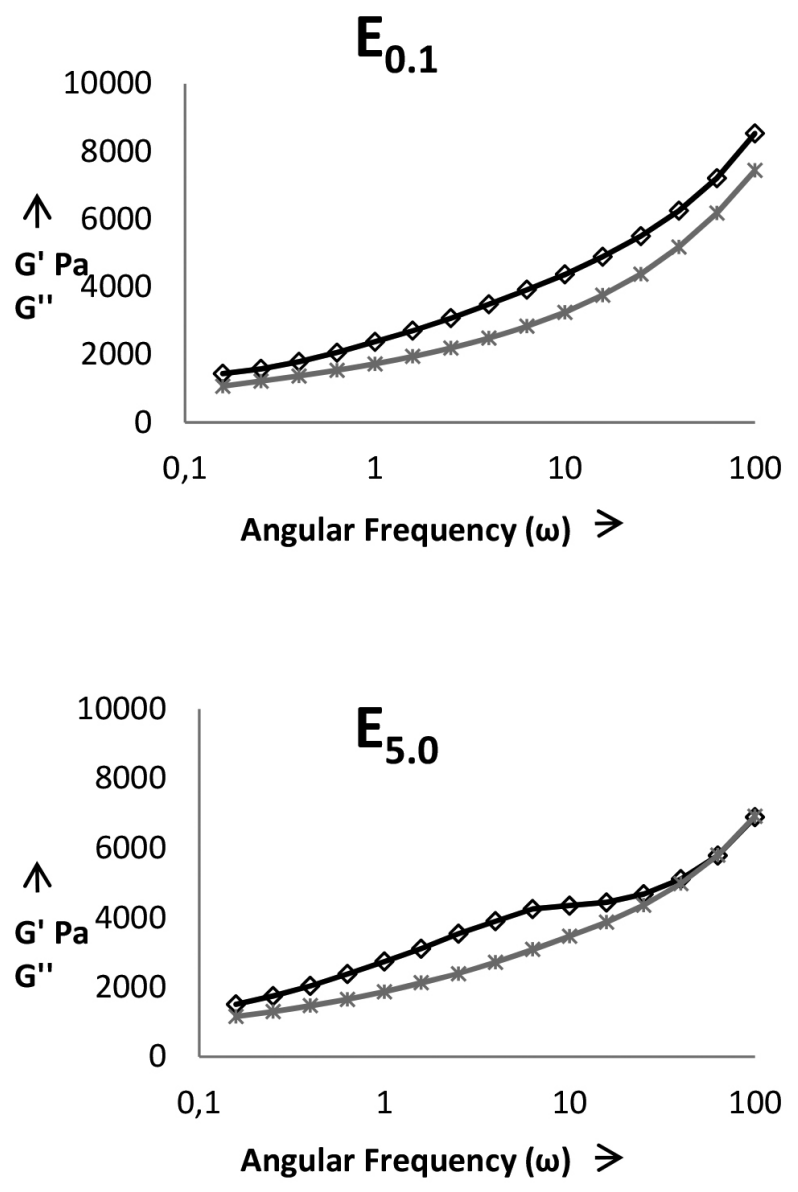
over the entire range of frequency investigated, with a slight increase in the slope at higher frequencies. The figure relates to the formulation $\mathrm{E}_{1.0}$ at $25^{\circ} \mathrm{C}$, and it can be observed that $\mathrm{G}$ ' is also higher than $\mathrm{G}$ ', which is reversed with increasing frequency, indicating that at this ratio the formulation undergoes a state transition from elastic solid to viscous liquid. This behavior indicates a greater instability for the semissolid formulation, changing from an initially solid formulation to a more viscous one.

Finally, the formulation $\mathrm{E}_{5.0}$, at $25{ }^{\circ} \mathrm{C}$, also showed higher $\mathrm{G}$ ' values than G" values, although they were almost the same at high frequencies. This indicates that with an increase in the proportion of the active component, even with a disturbance in the elastic interactions at high frequencies, the system maintains solid elastic characteristics and solid/liquid transitions do not occur in the system. In the emulsified or polymeric formulations, for a well-defined molecular structure, dynamic results can be used for variations related to increasing the proportion of extract. ${ }^{32}$ The results of these tests may indicate that due to the complex molecular structure of plant extracts the proportion used can influence the degree of interaction with the formulation components, and the effect can vary depending on the frequency of the elastic modulus. In addition, this data may be directly related to the stability of the formulations. ${ }^{33}$ Thus, formulations that have not undergone a solid/liquid transition tend to have greater stability.

\section{Accelerated stability}

The behavior of the formulations containing pomegranate extract in different concentrations was similar to that found during the preliminary stability evaluation. Thus, with no significant physicochemical changes in the formulations of interest, the formulation containing the highest concentration of extract $\left(\mathrm{E}_{5.0}\right)$ was chosen for the accelerated stability studies. The parameters used to evaluate the accelerated stability (macroscopic analysis, spreadability determination, and $\mathrm{pH}$ ) demonstrated that the macroscopic characteristics of the $\mathrm{E}_{\mathrm{Br}}$ and $\mathrm{E}_{\mathrm{BHT}}$ formulations remained constant during the whole study period, regardless of the temperature applied in the tests. The same was observed for the samples containing

\section{Test $4^{\circ} \mathrm{C}$}
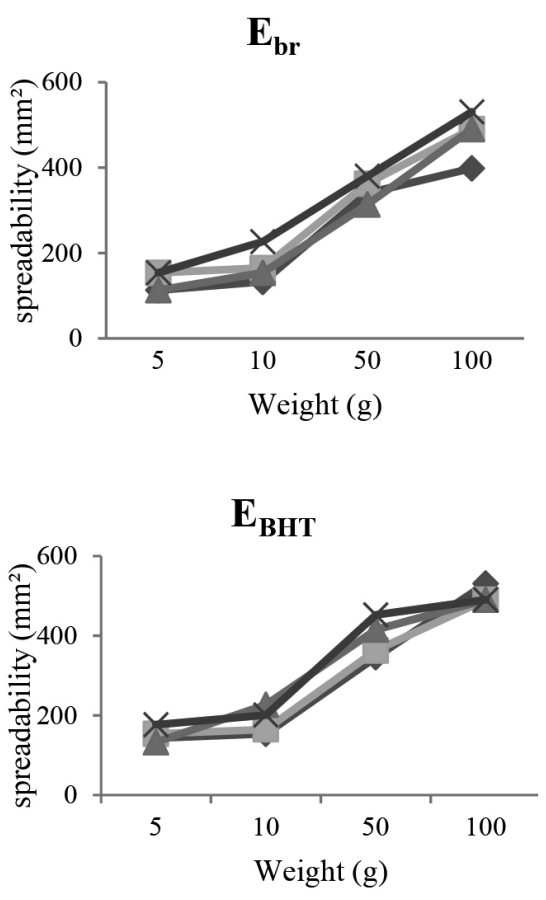

$\mathbf{E}_{5.0}$

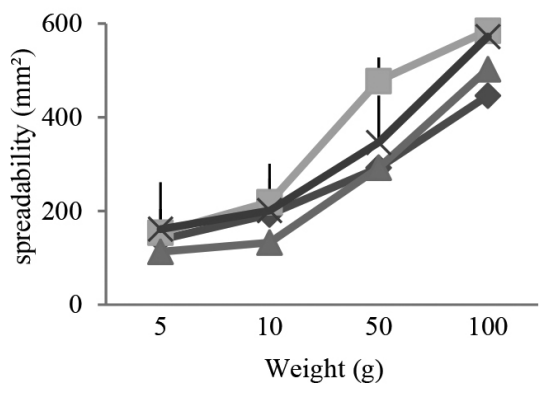

Test $25^{\circ} \mathrm{C}$

$\mathbf{E}_{\mathrm{Br}}$

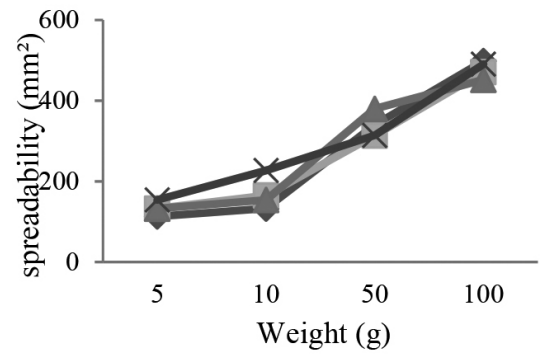

$\mathbf{E}_{\text {BHT }}$

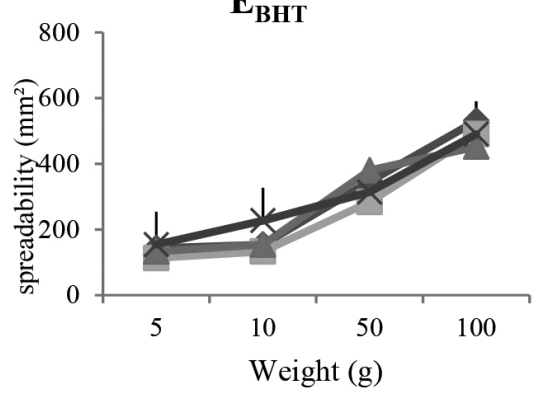

$\mathbf{E}_{5.0}$

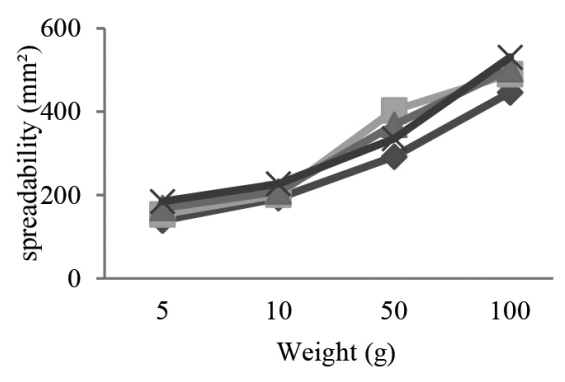

Test $45^{\circ} \mathrm{C}$

$\mathbf{E}_{\mathbf{B r}}$

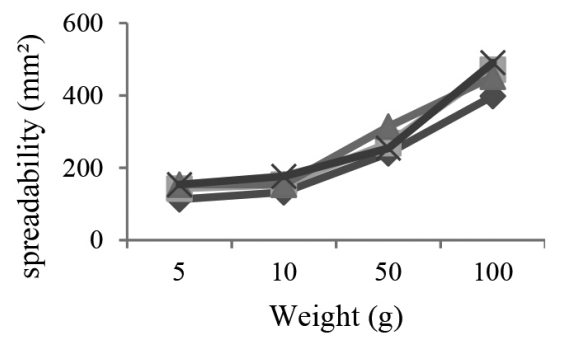

$\mathbf{E}_{\text {BHT }}$

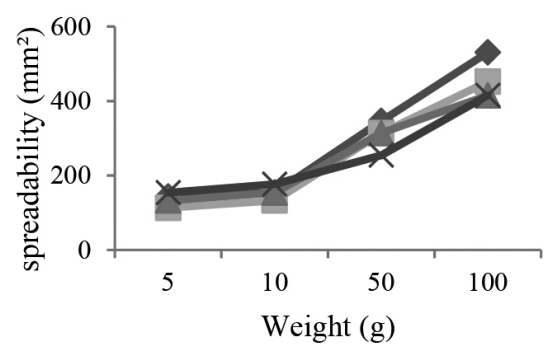

$\mathbf{E}_{5.0}$

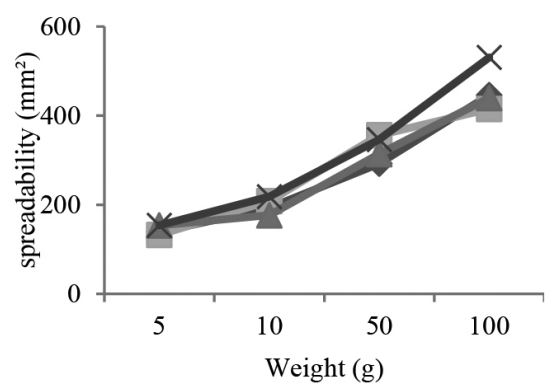


Table 3. Results for sample pH obtained in the accelerated stability study

\begin{tabular}{|c|c|c|c|c|c|c|}
\hline & Temperature & Day zero & Day 30 & Day 60 & Day 90 & $\begin{array}{c}\text { Relative standard } \\
\text { deviation }(\%)\end{array}$ \\
\hline & $4.0 \pm 2.0^{\circ} \mathrm{C}$ & $4.58( \pm 0.07)$ & $4.01( \pm 0.05)$ & $4.18( \pm 0.05)$ & $4.19( \pm 0.06)$ & 5.68 \\
\hline \multirow[t]{3}{*}{ EXTRACT } & $25.0 \pm 2.0^{\circ} \mathrm{C}$ & $4.58( \pm 0.07)$ & $4.24( \pm 0.22)$ & $4.36( \pm 0.10)$ & $4.29( \pm 0.05)$ & 3.43 \\
\hline & $45.0 \pm 2.0^{\circ} \mathrm{C}$ & $4.58( \pm 0.07)$ & $3.81( \pm 0.05)$ & $3.88( \pm 0.07)$ & $3.97( \pm 0.12)$ & 8.68 \\
\hline & $4.0 \pm 2.0^{\circ} \mathrm{C}$ & $6.99( \pm 0.05)$ & $6.58( \pm 0.02)$ & $6.37( \pm 0.05)$ & $5.25( \pm 0.04)$ & 4.60 \\
\hline \multirow[t]{3}{*}{$\mathbf{E}_{\mathrm{Br}}$} & $25.0 \pm 2.0^{\circ} \mathrm{C}$ & $6.99( \pm 0.05)$ & $6.32( \pm 0.03)$ & $6.56( \pm 0.11)$ & $4.35( \pm 0.03)$ & 19.32 \\
\hline & $45.0 \pm 2.0^{\circ} \mathrm{C}$ & $6.99( \pm 0.05)$ & $6.38( \pm 0.02)$ & $6.34( \pm 0.17)$ & $4.73( \pm 0.07)$ & 15.82 \\
\hline & $4.0 \pm 2.0^{\circ} \mathrm{C}$ & $6.78( \pm 0.08)$ & $6.63( \pm 0.19)$ & $5.97( \pm 0.15)$ & $6.33( \pm 0.07)$ & 5.57 \\
\hline \multirow[t]{3}{*}{$\mathbf{E}_{\text {BHT }}$} & $25.0 \pm 2.0^{\circ} \mathrm{C}$ & $6.78( \pm 0.08)$ & $6.64( \pm 0.01)$ & $5.80( \pm 0.14)$ & $6.33( \pm 0.04)$ & 6.80 \\
\hline & $45.0 \pm 2.0^{\circ} \mathrm{C}$ & $6.78( \pm 0.08)$ & $6.56( \pm 0.02)$ & $5.06( \pm 0.16)$ & $6.19( \pm 0.05)$ & 12.44 \\
\hline & $4.0 \pm 2.0^{\circ} \mathrm{C}$ & $5.58( \pm 0.07)$ & $5.01( \pm 0.05)$ & $5.18( \pm 0.05)$ & $5.19( \pm 0.06)$ & 4.60 \\
\hline \multirow[t]{2}{*}{$\mathbf{E}_{5.0}$} & $25.0 \pm 2.0^{\circ} \mathrm{C}$ & $5.58( \pm 0.08)$ & $5.24( \pm 0.22)$ & $5.36( \pm 0.10)$ & $5.29( \pm 0.05)$ & 2.79 \\
\hline & $45.0 \pm 2.0^{\circ} \mathrm{C}$ & $5.58( \pm 0.07)$ & $4.81( \pm 0.05)$ & $4.88( \pm 0.07)$ & $4.97( \pm 0.12)$ & 6.97 \\
\hline
\end{tabular}

pomegranate extract $\left(\mathrm{E}_{5.0}\right)$ at room temperature and with cooling. However, for the emulsions $\left(\mathrm{E}_{5.0}\right)$ kept in the incubator, there was a slight enhancement of the color during the 90-day study period. This result corroborates the findings of Balogh, ${ }^{11}$ who evaluated the stability of pomegranate glycolic extract and observed that samples stored in an incubator also showed a darkening of the color in the course of the study. In addition to this feature, Balogh observed an odor reduction under incubator and refrigerator conditions, which did not occur in our study. Therefore, it appears that the physical changes in the formulations containing the extract, stored in an incubator, may be the result of the acceleration of oxidation reactions, which culminates with the intensification of the color of the formulation. ${ }^{34}$

The spreadability is an important parameter related to the uniformity of the cream on the skin and the product stability. Figure 4 shows the results of the spreadability study for samples at different temperatures $\left(4^{\circ} \mathrm{C}, 25^{\circ} \mathrm{C}\right.$ and $\left.45^{\circ} \mathrm{C}\right)$. The spreadability of formulations showing similar behavior and there was no significant difference between the base values for maximum spreadability with increasing storage temperature. Thus, with the incorporation of the extract the cream spreadability was maintained. Formulations with BHT presented slightly lower spreadability than the other formulations, although the values showed no statistical difference. This is probably due to the moisture loss, therefore there is one dryness of cream. ${ }^{18}$

The results obtained for the $\mathrm{pH}$ are shown in Table 3. According to these data, it can be observed that, at the temperatures studied, the formulations containing pomegranate bark extract showed less $\mathrm{pH}$ variation during the analysis. On the other hand, the $\mathrm{E}_{\mathrm{Br}}$ and $\mathrm{E}_{\mathrm{BHT}}$ formulations showed large variations in this parameter over time, with relative standard deviations higher than the values recommended by legislation, ${ }^{18}$ except for the sample kept at room temperature. Therefore, the formulation prepared in this study again showed greater stable than that containing an antioxidant currently widely in use (BHT).

The formulation containing the extract had the lowest $\mathrm{pH}$, which is expected since ethanolic extracts are acidic. A change in the $\mathrm{pH}$ could indicate chemical changes, demonstrating the instability of the extract with the anionic cream. However, the extract showed no significant change in terms of $\mathrm{pH}$ after being incorporated into the anionic emulsion, even at different temperatures, throughout the test, verifying that the formulation does not demonstrate chemical instability, such as oxidation, which would lead to a loss of the antioxidant activity of the cream. This is another factor that corroborates the claim that the new formulation is stable over time. Another important aspect is that, although the $\mathrm{pH}$ of the skin is slightly acid (4.6 to 5.8), ${ }^{35}$ the formulation has appropriate $\mathrm{pH}$ for use as a cosmetic product without being aggressive. The $\mathrm{pH}$ of $\mathrm{E}_{\mathrm{BHT}}$ was reduced after 60 days but it returned to the initial $\mathrm{pH}$ after 90 days, therefore the study ending with no significant difference in this parameter $(\mathrm{p}<0.05)$. In contrast the $\mathrm{pH}$ of $\mathrm{E}_{\mathrm{Br}}$ was reduced after 60 days and this feature occurred by absence of antioxidants agents in formulation. Probably this reduction has been occurred by redox and / or hydrolysis reactions of formulations components having significant difference in this parameter $(\mathrm{p}<0.05){ }^{18}$

\section{CONCLUSIONS}

In this study we developed pharmaceutical semissolid formulations capable of serving as a vehicle for different concentrations of an ethanolic extract of pomegranate bark. These formulations maintained the antioxidant activity of the extract and also showed physical and chemical stability. The pomegranate extract proved to be a promising antioxidant, being equivalent to BHT, as the isolated extract or for incorporation into a semissolid formulation.

\section{ACKNOWLEDGMENT}

The authors are grateful to UFMT for financial support.

\section{REFERENCES}

1. Barbosa, K. B.; Costa, N. M. B.; Alfenas, R. C. G.; Paula S. O.; Minim, V. P. R.; Bressan, J.; Rev. Nutr. 2010, 23, 629.

2. Atkins, P.; Jones, L.; Princípios de química: questionando a vida moderna e o meio ambiente, Bookman: Porto Alegre, 2006.

3. Haslam, E.; J. Nat. Prod. 1996, 59, 205.

4. Soares, S. E.; Rev. Nutr. 2002, 15, 71.

5. Jardini, F. A.; Macini Filho, J.; Rev. Bras. Cienc. Farm. 2007, 43, 137.

6. Morais, S. M; Catunda Junior, F. E. A.; Silva, A. R. A.; Martins Neto, J. S.; Quim. Nova. 2006, 29, 907.

7. Bernaud, F. S. R.; Funchal, C.; Nutrição Brasil 2011, 10, 310.

8. Contri, R. V.; Külkamp-Guerreiro, I. C.; Krieser, K.; Pohlmann, A. R.; Guterres, S. S.; J. Cosmet. Sci. 2014, 65, 299.

9. Gettens, L.; Frasson, A.P.Z.; Revista Contexto \& Saúde 2007, 12, 41. 
10. Lansky, E. P.; Newman, R. A.; J. Ethnopharmacol. 2007, 109, 177.

11. Balogh, T. S.; Dissertação de Mestrado, Universidade de São Paulo, Brasil, 2011.

12. Agência Nacional de Vigilância Sanitária - ANVISA. Formulário de Fitoterápicos da Farmacopeia Brasileira. Brasília, 10 de novembro de 2011.

13. Agência Nacional de Vigilância Sanitária - ANVISA. Formulário Nacional da Farmacopeia Brasileira. Brasília, de 2012.

14. Rio, R. G. W.; Dissertação de Mestrado, Universidade de São Paulo, Brasil, 1996.

15. Carpes, S. T.; Prado, A.; Moreno, I. A. M.; Mourão, G. B.; de Alencar, S. M.; Masson, M. L.; Quim. Nova 2008, 31, 1660.

16. Andrade, C. A.; Costa, C. K.; Bora, K.; Miguel, M. D.; Miguel, O. G; Kerber, V. A.; Rev. Bras. Farmacogn. 2007, 17, 231.

17. Pianovski, A. R.; Vilela, A. F. G.; da Silva, A. A. S.; Lima, C. G.; da Silva, K. K.; Carvalho, V. F. M.; de Musis, C. R.; Machado, S. R. P.; Ferrari, M.; Rev. Bras. Cienc. Farm. 2008, 44, 249.

18. Agência Nacional de Vigilância Sanitária - ANVISA. Guia de Estabilidade de Produtos Cosméticos. Brasília, 10 de maio de 2004.

19. Ferrari, M.; Tese de Doutorado, Universidade de São Paulo, Brasil, 2002.

20. Borghetti, G. S.; Knorst, M. T.; Rev. Bras. Cienc. Farm. 2006, 42, 531.

21. Trindade, M. P.; Fonseca, L.; Juiz, P. J. L.; Brazilian Journal of Health Research 2009, 11, 49 .
22. Aluko, R. E.; Trends Food Sci. Technol. 2005, 16, 344

23. Naczk, M.; Shahidi, F.; J. Chromatogr. A. 2004, 1054, 95.

24. Sousa, C. M. M.; Silva, H. R.; Vieira-Jr, G. M.; Ayres, M. C. C.; Costa, C. L. S.; Araújo, D. S.; Cavalcante, L. C. D.; Barros, E. D. S.; Araújo, P. B. de M.; Brandão, M. S.; Chaves, M. H.; Quim. Nova 2007, 30, 351.

25. Gözlekçi, S.; Saraçoğlu, O.; Onursal, E.; Özge, M.; Pharmacogn. Mag. 2011, 7,161.

26. Georgetti, S. R.; Casagrande, R.; Moura-de-Carvalho V. F. T.; Verri Jr., W. A.; Fonseca, M. J.; Eur. J. Pharm. Biopharm. 2006, 64, 99.

27. Fischer, U. A.; Carle, R.; Kammerer, D. R.; Food Chem. 2011, 127, 807.

28. Montagner, D.; Correia, G.M.; Rev. Bras. Cienc. Farm. 2004, 85, 69.

29. Tadros, T.; Adv. Colloid Interface Sci. 2004, 108, 227.

30. Casteli, V. C.; Mendonça, C. C.; Campos, M. A. L.; Machado, S. R. P.; Acta Sci., Health Sci. 2008, 30, 121.

31. Vianna Filho, R. P.; Dissertação de Mestrado, Universidade Federal do Paraná, Brasil, 2009.

32. Schramm, G.; A practical approach to Rheology and Rheometry, $2^{\text {nd }}$ ed., Gebrueder HAAKE GmbH: Federal Republic of Germany, 2000.

33. Cotrim, A. C. M.; Honorio-França, A. C.; França, E. L.; Biointerface Res. Appl. Chem. 2016, 6, 1128

34. Campos, F. M.; Martino, H. S. D.; Sabarense, C. M.; Pinheiro-Santana, H. M.; Aliment. Nutr. 2008, 19, 481.

35. Leonardi, G. R.; Gaspar, L. R.; Campos, P. M. B. G. M.; An. Bras. Dermatol. 2002, 77, 563 . 